\title{
Profile of pegvisomant in the management of acromegaly: an evidence based review of its place in therapy
}

This article was published in the following Dove Press journal:

Research and Reports in Endocrine Disorders

16 February 2015

Number of times this article has been viewed

\author{
Ignacio Bernabeu' \\ Iria Adriana Rodriguez- \\ Gomez ${ }^{2}$ \\ Ana Maria Ramos-Levi ${ }^{3}$ \\ Monica Marazuela ${ }^{3}$ \\ 'Department of Endocrinology, \\ Complejo Hospitalario Universitario \\ de Santiago de Compostela, Santiago \\ de Compostela, Spain; ${ }^{2}$ Endocrine \\ Unit, Hospital HM Modelo, A Coruña, \\ Spain; ${ }^{3}$ Department of Endocrinology, \\ Hospital Universitario de la Princesa, \\ Instituto de Investigación Princesa, \\ Universidad Autónoma de Madrid, \\ Madrid, Spain
}

\begin{abstract}
Pegvisomant (PEG) is a genetically engineered growth hormone (GH) analog able to bind and block the GH receptor. PEG blocks all metabolic effects of GH hypersecretion, normalizes insulin-like growth factor I (IGF-I) level and paradoxically produces an increase in GH secretion. When PEG was commercialized, there were some concerns regarding whether the increased GH secretion could cause growth of the residual tumor or cause the overcoming of receptor blockade with loss of efficacy. PEG commercialization was followed by the onset of two main prospective observational studies aiming to evaluate the safety and outcome of PEG long-term treatment: the German Pegvisomant Observational Study and ACROSTUDY. These observational studies, along with several independent studies have provided comprehensive information regarding the actual use, efficacy and safety of long-term treatment with PEG. The efficacy of PEG in clinical setting is somewhat lower than that reported in the pivotal studies, nevertheless PEG normalizes IGF-I levels ranging between $65 \%$ and $97 \%$ of cases. Side effects in observational studies were uncommon and rarely caused discontinuation of treatment. Liver dysfunction developed in $2.5 \%$ of cases, was usually transient and no permanent liver damage was reported. Increased tumor size was developed by about $2.2 \%-3.2 \%$ of acromegalic patients treated with PEG, without differences to that described for other modalities of treatment. Only one third of cases corresponded with true growth after initiation of PEG treatment. Involved mechanism is currently unknown. New modalities of treatments by the combined use of PEG with somatostatin analog or cabergoline have been developed with promising results. Recently, two clinical guidelines written to optimize the use of these treatment modalities and to monitor possible adverse events have been published.
\end{abstract}

Keywords: acromegaly, pegvisomant, pituitary tumor, somatostatin analogs, cabergoline, IGF-I

\section{Profile of pegvisomant (PEG) in the management of acromegaly: an evidence based review of its place in therapy}

Acromegaly is a rare and chronic disease, which in more than $95 \%$ of cases is caused by a benign growth hormone (GH)-producing pituitary adenoma, determining an increased production of IGF-I. The clinical picture includes typical somatic changes, multiple general and local comorbidities (metabolic, endocrine, vascular, oncologic, neurologic, ophthalmologic, etc) and an increased mortality that can be corrected by optimal treatment. ${ }^{1}$

Correspondence: Ignacio Bernabeu Department of Endocrinology, Complejo Hospitalario Universitario de Santiago de Compostela, Travesía da Choupana s/n, I5706 Santiago de Compostela, Spain Email ignacio.bernabeu.moron@sergas.es; bernabeumoron@gmail.com

\section{Treatment for acromegaly}

The goals of treatment are normalization of GH/IGF-I levels, removal of the adenoma or at least reduction of its size avoiding local complications, preservation of pituitary 
function and early and rigorous treatment of all associated comorbidities. ${ }^{1}$ Transsphenoidal surgery is recommended as the primary treatment for most patients. However as GH/ IGF-I levels are normalized in only $40 \%-70 \%$ of cases, most acromegalic patients will require adjuvant medical treatment. $^{2}$

\section{Overview of medical treatment for acromegaly}

Medical treatment for acromegaly currently includes three groups of drugs: dopamine agonists, long acting somatostatin analogs (SSA), and PEG, a growth hormone receptor (GHR) antagonist.

SSA represent the first line medical treatment for acromegaly after unsuccessful surgery. SSA exert an anti-secretory and an antitumor effect decreasing $\mathrm{GH}$ and IGF-I levels and reducing the potential for tumor growth, even leading to a reduction in tumor size. ${ }^{3}$ The efficacy of SSA depends on tumor expression of different subtypes of somatostatin specific receptors (SSTR), ${ }^{4}$ on tumor expression of truncated SSTR variants ${ }^{5}$ and on the integrity of post-receptor pathways. ${ }^{6}$ Overall, the efficacy rate of SSA reaches 50\%-55\% and some additional patients show tumor response without biochemical control. ${ }^{3}$ Pasireotide is a second generation SSA with a broader binding affinity for SSTR, specially subtype 5. Pasireotide achieves biochemical control in 15\%-20\% of acromegalic patients non-controlled on first generation SSA treatment. ${ }^{7}$ However, hyperglycemiarelated adverse events may overcome the benefits of pasireotide in some patients. ${ }^{7}$

Cabergoline (CAB) exerts a mild but relevant antisecretory and anti-proliferative effect ${ }^{8}$ and may be useful in acromegalic patients with mild postoperative disease activity, especially in those with mixed $\mathrm{GH} /$ pituitary prolactin secreting adenomas. $\mathrm{CAB}$ has also the advantage of its lower cost and its more convenient oral administration. ${ }^{2,8}$ The use of $\mathrm{CAB}$ combined with $\mathrm{SSA}^{8}$ or $\mathrm{PEG}^{9,10}$ could provide an additional therapeutic improvement.

\section{PEG}

The GHR activation requires the sequential binding of one molecule of native GH to the site 1 and 2 of GHR dimer. This binding produces subtle conformational changes affecting extracellular and transmembrane domains of GHR allowing and triggering the Janus kinase 2 (Jak2) phosphorylation. Jak2 phosphorylation induces the recruitment and subsequent phosphorylation of signal transducers and activators of transcription (STAT 1, 3, 5A and 5B), allowing the formation of homo- and heterodimers of STAT, which are translocated to the nucleus to promote transcription of genes $(I G F-I)$. Furthermore, activation of Jak 2 is followed by the activation of ubiquitin conjugation system of GHR internalization. Under physiological conditions, the recycling of GHR is very fast (30-60 minutes), GHR is cleared by a dual mechanism: its proteolytic breakdown to generate $\mathrm{GH}$ binding protein (GHBP) and through a continuous process of ubiquitin-dependent internalization and endolysosomal degradation. ${ }^{11-13}$

PEG is a GH analog with nine amino acid changes, one (G120K) gives its antagonistic effect; the remaining amino acid changes maintain binding affinity to GHR; finally the compound is pegylated to extend its half-life. PEG binds to site 1 of GHR in competition with native GH but is unable to bind at site 2, preventing Jak2 phosphorylation and signal transduction. Additionally, it also blocks the activation of ubiquitin-dependent system, therefore GHR-PEG complex internalization is very slow, which may explain the increased generation of GHBPs observed during PEG treatment. ${ }^{14-16}$ The binding affinity of PEG to GHR is lower than the affinity of native $\mathrm{GH}$; nevertheless the affinities of both native GH and PEG to GHBP are similar ${ }^{17}$ This explains the high concentrations of PEG required for effective blocking of GHR. ${ }^{16,17}$ PEG produces a dose dependent reduction of serum IGF-I accompanied by significant improvements in the clinical expression of acromegaly and its comorbidities. ${ }^{16,18}$ At the same time, however, PEG causes an increase in GH secretion ${ }^{16}$ because of a reduced IGF-I feedback or/and from a direct effect on the pituitary. ${ }^{19}$ This increase in GH secretion reaches a plateau both in short-term ${ }^{18}$ and in long-term treatments. ${ }^{19}$ It should be noted that given the high structural homology between PEG and native GH, GH levels during PEG treatment can only be evaluated using assays specifically designed to avoid such interference. The use of commercially available assays leads to widely variable results, ${ }^{20}$ therefore its use is not recommended.

\section{Efficacy of PEG in preclinical studies}

In the first study (Table 1), published in 2000, Trainer et al ${ }^{18}$ included 112 patients in a 12- week randomized double blind study of three different daily doses of PEG versus placebo. After 12 weeks of treatment, the IGF-I level was normalized in $89 \%$ of patients treated with $20 \mathrm{mg}$ of PEG. GH concentration, determined by a modified radioimmunoassay to prevent cross reaction with PEG was increased 3, 9, and 14\% above baseline levels in the groups treated with 10, 15, and $20 \mathrm{mg}$ respectively. PEG treatment produced significant clinical 


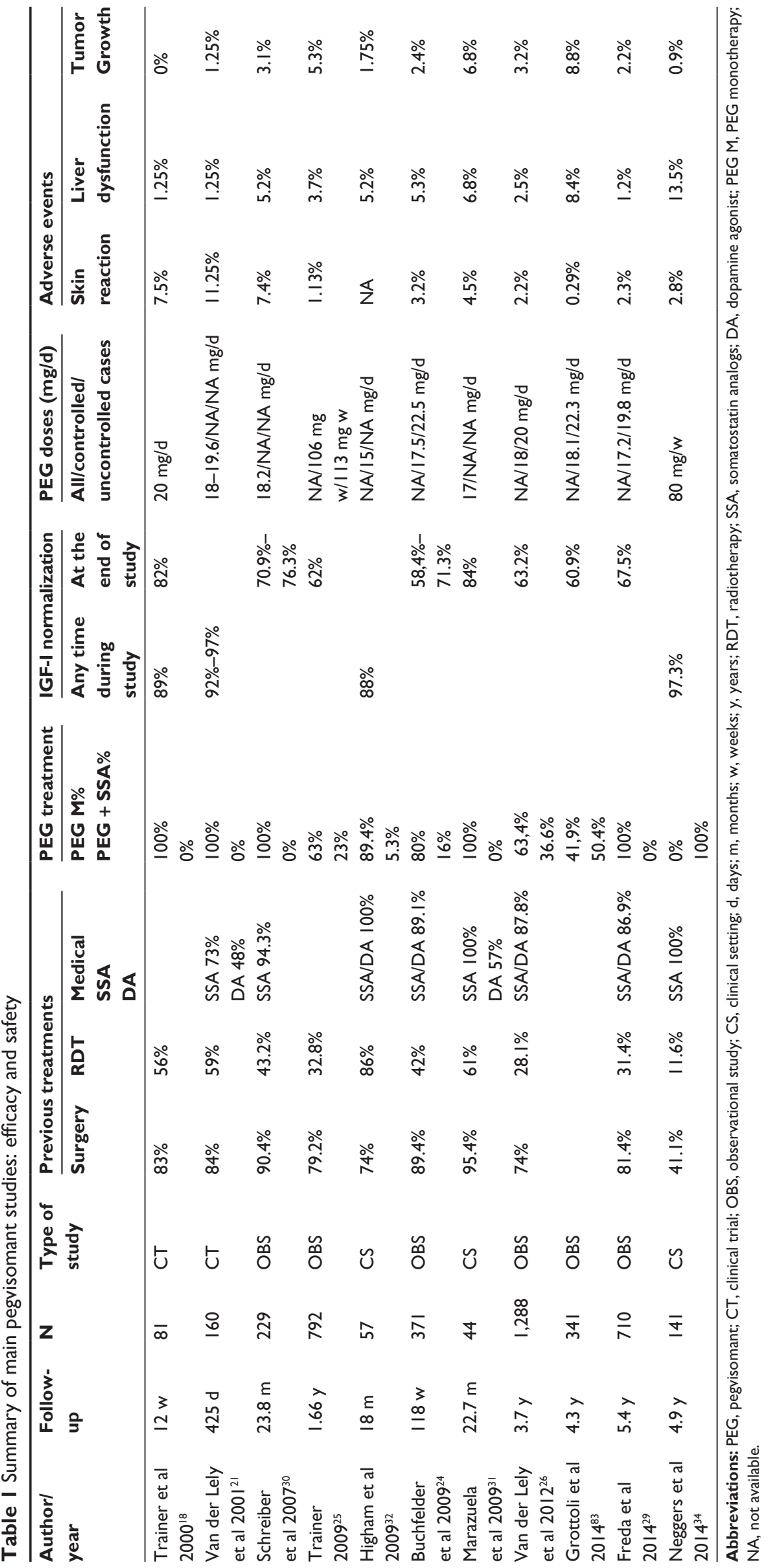


improvement and was well tolerated: six patients had mild local reactions at the injection site, one patient developed abnormal liver function tests and there were no significant changes in tumor volume. ${ }^{18}$

The second study published by Van der Lely et $\mathrm{al}^{21}$ in 2001, included 160 patients to evaluate the efficacy and safety of prolonged treatment (18 months) with PEG. Mean PEG doses were $14.7 \mathrm{mg}$ per day in the 6 months cohort $(n=131)$; $18 \mathrm{mg}$ per day in the 12 months cohort $(\mathrm{n}=90)$ and $19.6 \mathrm{mg}$ per day in the 18 months cohort $(n=39)$. IGF-I normalized at least once during follow-up in $97 \%$ of cases treated for at least 12 months. GH concentrations increased during the first 6 months of treatment and subsequently stabilized. Adverse effects included mild local reactions at the injection site in $11 \%$, two cases with significant liver dysfunction and two cases of tumor size progression requiring treatment. The efficacy and safety of PEG treatment was similar to the previously mentioned studies in two other small studies performed in acromegalic patients resistant to SSA. ${ }^{22,23}$ These results were expected, as PEG efficacy does not depend on the expression of SSTR by the tumor.

\section{Efficacy of PEG in clinical studies}

PEG was approved in November 2002 by the European Medicines Agency for patients with acromegaly with inadequate response to surgery and/or radiation therapy and in whom medical treatment with SSA did not normalize IGF-I level. The commercialization of PEG was followed by the onset of two prospective observational post-marketing studies aiming to evaluate the safety and outcome of PEG treatment: the German Pegvisomant Observational Study (GPOS) and the ACROSTUDY later merged into the global ACROSTUDY (Table 1). ${ }^{24}$

In the last report of GPOS, ${ }^{24}$ including more than $80 \%$ of all PEG prescriptions in Germany, the IGF-I normalization rate was between $65.3 \%$ and $71.3 \%$ with a mean PEG dose of $16.4 \mathrm{mg} /$ day (Table 1). Several interim analysis from ACROSTUDY have been published. ${ }^{25-28}$ The last publication $^{26}$ included 1,288 patients. After 5 years of PEG treatment, $63.2 \%$ of cases had normal IGF-I levels. Mean dosages were $18 \mathrm{mg} /$ day for the controlled group and $20 \mathrm{mg} /$ day for the uncontrolled group (Table 1). A recent report from ACROSTUDY, including only patients treated with PEG monotherapy $(\mathrm{n}=710)$ found similar results: $67.5 \%$ of IGF-I normalization at 5 years with a mean PEG dose of $17.2 \mathrm{mg} /$ day $^{29}$ (Table 1). Several causes could explain the lower than expected efficacy of PEG in clinical studies compared to the results observed in pivotal studies
(Table 2). Nevertheless, several small and prospective studies performed in centers with higher experience in acromegaly treatment ( $28 \%$ of participant sites in GPOS included only one patient), ${ }^{30}$ reported IGF-I normalization rates similar to the ones described in preclinical studies ranging from $84 \%$ to $97 \%$ (Table 1$){ }^{31-34}$

\section{PEG, glucose metabolism and cardiovascular risk factors}

Impaired glucose tolerance and overt type 2 diabetes mellitus are frequent $(15 \%-38 \%)$ in the setting of acromegaly. ${ }^{2}$ The effects on glucose metabolism of different treatments modalities have been reviewed elsewhere, ${ }^{35}$ and can be summarized as follows: 1) surgical cure normalizes glucose tolerance and insulin resistance in acromegaly. 2) SSA treatment has a divergent effect on glucose metabolism: a positive one lowering GH/IGF-I levels, decreasing insulin resistance and a negative effect suppressing insulin secretion. ${ }^{35,36}$ A recent meta-analysis showed that SSA have a minor impact on glucose homeostasis in acromegaly, ${ }^{36}$ although some controversy persists, ${ }^{37}$ and 3) PEG has positive effects on glucose metabolism in acromegaly. ${ }^{38-42}$ PEG does not exert any direct effect on pancreatic $\beta$-cell function and unlike SSA it does not suppress insulin secretion. PEG decreases insulin resistance and improves insulin sensitivity. Therefore PEG decreases blood glucose, $\mathrm{HbA}_{1 \mathrm{c}}$, insulin levels, and homeostasis model assessment (HOMA) index and reduces the need for hypoglycemic treatment in diabetic patients..$^{30,31,38,40}$ PEG may be useful when diabetes mellitus is a comorbidity of acromegaly. ${ }^{2}$ This positive effect

Table 2 Possible causes of lower than expected efficacy of PEG in clinical studies compared to the results observed in pivotal studies

I. Failure of dose titration

2. Failure in patients' compliance

3. Methodological issues regarding IGF-I assays

4. Problems with increasing dose above $20 \mathrm{mg} /$ day with the currently available formulations or because of economic issues

5. Different criteria used to assess IGF-I normalization between preclinical (lowest IGF-I criteria: even a single normal IGF-I during the follow-up was classified as IGF-I normalization) and observational studies (latest IGF-I criteria: normal IGF-I level on a cross-sectional manner at a predefined time or at the last follow-up)

6. Temporary loss of IGF-control requiring a dosage adjustment (occurring in $34 \%-48 \%$ of patients) $)^{30,33}$

7. Some of the uncontrolled cases in observational studies probably represent transient changes of IGF-I levels due to dose adjustments, IGF-I assays' variations or alternatively mild elevations of IGF-I (ie, IGF-I $>$ I $\times$ ULN and $<$ I.3 $\times$ ULN) for which the corresponding physician does not deem it necessary to adjust PEG dosage

Abbreviations: PEG, pegvisomant; ULN, upper limit of normal. 
of PEG is lost in those patients on combined treatment with SSA. ${ }^{43}$

PEG treatment improves blood pressure, especially diastolic pressure, reduces cardiac mass, and exerts beneficial effects on rhythm disorders. ${ }^{44}$ The effect of PEG treatment on lipid profile is controversial: some studies did not find any change, ${ }^{44}$ while others found an increase in total and low-density lipoprotein cholesterol without change in triglyceride levels and a reduction in lipoprotein (a) levels. ${ }^{45,46}$ PEG therapy is associated with a reduction of cardiovascular risk. $^{44}$

\section{PEG and pregnancy}

A recent article reviewing all available data on pregnancy outcome in acromegalic patients exposed to PEG (35 pregnancies) did not suggest adverse effects of PEG therapy during pregnancy. ${ }^{47}$ However, the information about safety of PEG and SSA treatments during pregnancy is very limited and both drugs must be discontinued, preferably prior to conception. Current guidelines only recommend medical treatment during pregnancy, mainly dopamine agonist, for tumor and headache control. ${ }^{2}$

\section{Combined treatment: PEG plus SSA and/or CAB}

The use of SSA with their antisecretory and antitumor effect, combined with the blockage of $\mathrm{GH}$ actions obtained with PEG result in an attractive therapeutic option for patients with acromegaly.

\section{PEG plus long acting SSA}

The first study regarding combined PEG and SSA treatment, ${ }^{48}$ included 26 acromegalic patients who were biochemically resistant to SSA. PEG was added from $25 \mathrm{mg} /$ week to a maximum allowed weekly dose of $80 \mathrm{mg}$. IGF-I normalization was achieved in $95 \%$ of cases with a mean PEG dose of $60 \mathrm{mg} /$ week. Tumor size did not increase but $38 \%$ of patients developed liver dysfunction. The authors highlighted the similar efficacy of this combined treatment to PEG monotherapy with a lower economic cost and with a possible improvement in compliance. Later, the same group published several articles that included a larger number of patients and longer follow-up with consistent results. ${ }^{34,49}$ Additionally, they reported an improvement in quality of life after the addition of $40 \mathrm{mg}$ PEG weekly in acromegalic patients who had already normalized IGF-I on SSA monotherapy. ${ }^{50}$ In their most recent publication, ${ }^{34} 141$ patients were treated with SSA plus PEG during 4.9 years. PEG plus SSA treatment was the primary treatment in $58 \%$ of cases. Normalization of IGF-I (lowest IGF-I criteria) was observed in $97.3 \%$ of patients with a median weekly PEG dose of $80 \mathrm{mg}$. IGF-I normalization rate was not significantly different between patients who had undergone prior pituitary surgery and those receiving primary medical treatment, nor between micro- or macroadenoma or regarding sex. Tumor size decreased in $16.9 \%$ and increased in one case $(0.9 \%)$. Transient liver dysfunction (ALS/AST $>3 \times$ ULN [upper limit of normal]) was observed in $13.5 \%$ and injection-site reactions were present in $2.8 \%$. However, other studies reported worse results. The efficacy of PEG monotherapy versus PEG plus SSA combined treatment was similar: 56 versus $62 \%$ in a 40 -week, open-label, prospective and randomized study ${ }^{51}$ with acromegalic patients resistant to octreotide-LAR. However, liver dysfunction tended to be more frequent with the combined treatment. Reductions in fasting glucose levels were greater with PEG monotherapy as previously described. ${ }^{40,52}$ In another study, ${ }^{53}$ long acting lanreotide plus PEG during 7 months normalized IGF-I at the end of study in $57.9 \%$ of cases and at any time in $78.9 \%$ of patients with a median PEG dose of $60 \mathrm{mg}$ / week. Efficacy was lower in diabetic subjects. Tumor size decreased in $13.2 \%$ and increased in $24.5 \%$. The prevalence of liver dysfunction was $11 \%$.

Current guidelines suggest, as a weak recommendation with low quality evidence, that combined medical therapies may improve efficacy, reduce side effects, decrease the frequency of injections and total drug dose, and, potentially offer a cost benefit and improved compliance, suggesting the addition of PEG in a patient with inadequate response to SSA. ${ }^{2}$ Combination therapy, usually with daily $\mathrm{PEG},{ }^{26}$ is increasingly being used in recent years. While in the GPOS no cases of combined treatment were described, ${ }^{30}$ in the ACROSTUDY $2009,{ }^{27} 22.4 \%$ of the patients were receiving combination therapy with PEG plus SSA and 3.8\% PEG plus SSA plus CAB. In ACROSTUDY 2012, ${ }^{26} 36.6 \%$ of subjects were on combination therapy. In clinical practice, many of these treatments are given in order to maintain the antitumor effect of SSA, even in patients with minimal residual tumors.

\section{PEG plus $C A B$}

Two small studies have shown that the combination of PEG and $\mathrm{CAB}$ might be useful. In a prospective trial of 24 patients, addition of PEG (10 mg daily, fixed dose) to CAB increased IGF-I normalization from $11 \%$ to $68 \%$, and subsequent discontinuation of $\mathrm{CAB}$ decreased the control rate to $26 \%{ }^{9}$ Similarly, in a retrospective study of 14 acromegalic patients 
uncontrolled with PEG (10-30 mg/d), the addition of CAB up to a final dose of $1.5 \pm 0.7 \mathrm{mg} / \mathrm{wk}$ decreased IGF-I levels by $18 \% \pm 27.2 \%$, and normalized IGF-I in $28 \%$ of patients. ${ }^{10}$

\section{Determinants of PEG doses}

Several clinical, biochemical, and perhaps molecular aspects may be related to the PEG dose required to normalize IGF-I (Table 3). Firstly, there is a direct correlation between baseline GH and IGF-I levels and PEG doses required for IGF-I normalization. Differences between sexes should also be taken into account. Women secrete greater amounts of GH than men, however estrogens produce liver resistance to $\mathrm{GH}$ by inhibition of JAK2 phosphorylation mediated by SOCS-2, and as a result women have lower IGF-I concentrations. GHBP concentrations are also higher in women through an unexplained mechanism..$^{54,55}$ Consequently, women require a significantly greater PEG dose than men. ${ }^{56}$ Some other factors have been related to the PEG doses required for IGF-I normalization. For instance, patients who underwent pituitary radiation require less PEG dosage, ${ }^{31,56}$ whilst overweight patients require higher doses. ${ }^{56,57}$ Diabetes mellitus is also associated with worse response to PEG therapy. ${ }^{43,53}$ This has been observed in the German cohort of ACROSTUDY where

Table 3 Determinants of pegvisomant dosage

\begin{tabular}{|c|c|c|}
\hline Determinant & Effect & Reference \\
\hline $\begin{array}{l}\text { GH level/IGF-I } \\
\text { level }\end{array}$ & $\begin{array}{l}\text { Direct correlation with PEG required } \\
\text { dose }\end{array}$ & 56 \\
\hline Sex & $\begin{array}{l}\text { Higher GH and GHBP levels with } \\
\text { lower IGF-I level in women. Requiring a } \\
\text { weight-corrected PEG dose } 4.7 \mathrm{mg} / \text { day } \\
\text { higher than in men }\end{array}$ & $31,54-56$ \\
\hline Radiotherapy & $\begin{array}{l}\text { Irradiated patients require } 3.3 \mathrm{mg} / \text { day } \\
\text { less PEG dose }\end{array}$ & 31,56 \\
\hline Weight & $\begin{array}{l}\text { PEG dose required increases with body } \\
\text { weight }\end{array}$ & 56 \\
\hline $\begin{array}{l}\text { Diabetes } \\
\text { mellitus (type 2) }\end{array}$ & $\begin{array}{l}\text { Higher insulin level, higher expression of } \\
\text { hepatic GHR, higher required PEG dose }\end{array}$ & 56 \\
\hline $\begin{array}{l}\text { SSA co- } \\
\text { treatment }\end{array}$ & $\begin{array}{l}\text { Lower insulin level, lower expression of } \\
\text { hepatic GHR, lower required PEG dose }\end{array}$ & 48,58 \\
\hline \multirow[t]{3}{*}{ d3-GHR } & $\begin{array}{l}\text { More severe disease and lower rate of } \\
\text { IGF-I normalization after surgery and } \\
\text { SSA therapy }\end{array}$ & 62 \\
\hline & $\begin{array}{l}\text { d3-GHR patients required lower PEG } \\
\text { doses and fewer months to normalize } \\
\text { IGF-I }\end{array}$ & 63,64 \\
\hline & d3-GHR not related to PEG dose & 65 \\
\hline $\begin{array}{l}\text { IGF-I } \\
\text { (cyto-adenosine }\end{array}$ & $\begin{array}{l}\text { IGF-I } 194 \text { bp allele ( } 20 \text { CA repeats): } \\
\text { more resistant to therapies }\end{array}$ & 66 \\
\hline $\begin{array}{l}\text { (CA) repeats in } \\
\text { IGF-l gene) }\end{array}$ & $\begin{array}{l}\text { IGF-I (CA repeats) no influence on } \\
\text { outcome }\end{array}$ & 67 \\
\hline
\end{tabular}

Abbreviations: $\mathrm{GH}$, growth hormone; SSA, somatostatin analogs; GHR, growth hormone receptor; PEG, pegvisomant; GHBP, growth hormone binding protein.
IGF-I normalization rates were lower in diabetic patients (64\%) than in non-diabetic ones $(75 \%)$. Furthermore, the dose of PEG required for IGF-I normalization was higher in diabetic patients $(18.9 \mathrm{mg} /$ day $)$ when compared to nondiabetic ones $(15.5 \mathrm{mg} /$ day). Additionally diabetic patients treated with insulin required higher PEG doses $(22.8 \mathrm{mg} /$ day $)$ than those treated with oral hypoglycemic agents $(17.2 \mathrm{mg} /$ day). ${ }^{43}$ A possible explanation for these findings is the role of insulin as one of the main regulators of GHR liver expression. ${ }^{58}$ In this regard, hyperinsulinemic diabetic patients (especially insulin treated cases) exhibit an increased expression of hepatic GHR, ${ }^{59-61}$ thus requiring higher concentrations of PEG for full receptor blockage. In contrast, SSA concomitant treatment reduces insulin secretion and portal insulin concentration leading to a decreased expression of hepatic GHR. ${ }^{58}$ In fact, this could explain the increase in serum PEG concentration (20\%) observed during PEG plus SSA treatment ${ }^{52}$ and the lower PEG dose required when this combined approach is used. ${ }^{48}$ Several pharmacogenomics aspects potentially related to the efficacy of PEG treatment have also been explored (Table 3). ${ }^{62-67}$

\section{PEG safety}

ACROSTUDY has provided comprehensive data regarding the safety of treatment with PEG. Any untoward medical condition reported in patients included in ACROSTUDY was considered as an adverse event. Thirty-seven percent of patients $(1,288)$ participating in ACROSTUDY developed an adverse event, of which $9.6 \%$ were considered as related to treatment. ${ }^{26}$ Serious adverse events were reported in $12.3 \%$ of patients and in $2 \%$ were considered as related to treatment. Only $1.7 \%$ of patients discontinued PEG due to a serious adverse event, of which only $0.3 \%$ were directly related to PEG. ${ }^{26}$

\section{Pituitary tumor size}

The possibility that the loss of negative feedback of IGF-I with increasing GH level would lead to the growth of residual tumor has been the main concern of PEG treatment, especially after the two first cases were reported. ${ }^{21}$ Theoretically the effect of PEG on the tumor should be neutral as on the pituitary (not protected by the blood-brain barrier) the possible effect of GH hypersecretion on tumor cells is blocked by PEG itself.

The optimal evaluation of changes in tumor size and the possible mechanisms involved in tumor growth are detailed in Table 4. In the GPOS study, ${ }^{68}$ an increase in tumor size was confirmed in eight cases $(2.6 \%)$ : two were related to SSA withdrawal, three had already had tumor growth during 
Table 4 Tumor changes evaluation and mechanisms of tumor growth

Evaluation of changes in tumor size requires: I) standardized MRI protocol; 2) a skilled neuroradiology team and; 3) the review of all previous radiological studies. Forty to fifty percent of suspected tumor growths are not confirmed after this careful evaluation..$^{26,68}$

\section{Mechanism of tumor Frequency Comments} growth

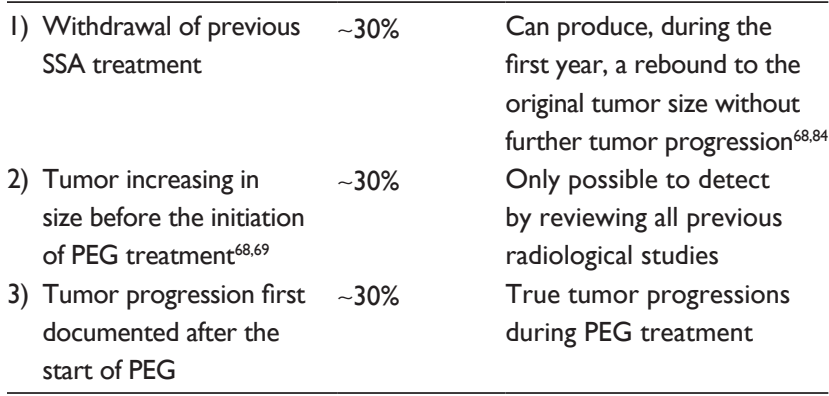

Abbreviations: PEG, pegvisomant; MRI, magnetic resonance imaging; SSA, somatostatin analogs.

previous SSA therapy and three were true tumor progression during PEG therapy. In all cases, the tumor increase was not considered clinically significant and PEG treatment was not discontinued. In this study, the endogenous GH concentrations (measured with a specific GH assay with no interference with PEG) were significantly higher in patients with tumor growth than in patients without evidence of tumor growth.

Changes in tumor volume during ACROSTUDY, based on local and central pituitary magnetic resonance imaging (MRI) readings are outlined in Table 5. Overall, 3.2\% of patients had an increase or increase/decrease of tumor size. ${ }^{26}$ Interestingly an additional study from ACROSTUDY including only those patients treated only with PEG as monotherapy

Table 5 Changes in tumor size during ACROSTUDY, local versus central MRI readings

ACROSTUDY: Pituitary MRI local evaluation ( $N=936$ with mean follow-up 3.7 years)

No change in tumor size $78.8 \%$

Changed tumor size $\quad 21.2 \%$

Decrease $\quad 12.6 \%$

Increase $\quad 7.2 \%$

Both increase and decrease $\quad 1.4 \%$

MRI central re-evaluation in a subset of $\mid 28$ cases: $|2|$ of them with changes in tumor size reported on local evaluation

No change in tumor size $32 \%$

Changed tumor size $\quad 53.1 \%$ Decrease $29.7 \%$ Increase $\quad 17.9 \%$

Both increase and decrease $5.4 \%$

Insufficient data for $\quad 14.8 \%$

diagnosis

Central re-evaluation of pituitary MRI only confirmed $53.1 \%$ of tumor changes locally reported

Abbreviation: MRI, magnetic resonance imaging. $(n=710)$ followed for a mean time of 3.8 years, found tumor growth in $2.2 \%$ of cases. ${ }^{29}$

In those cases with true tumor progression after the start of PEG it is difficult to identify whether the increase is related to treatment or is just the natural history of the tumor (Figure 1). In a large study, ${ }^{69}$ including 75 SSA-resistant patients followed for 29 months on PEG monotherapy, tumor growth was identified in five cases $(6.7 \%)$. In two of them tumor growth was identified during previous SSA treatment. Only two clinical factors were potentially associated with tumor growth: no previous radiotherapy and the duration of previous treatment with SSA, which was shorter in patients who experienced tumor growth. Extensive histological and molecular studies including analysis of SSTR1, 2, 3, and 5; sst5TMD4, st5TMD5, somatostatin, dopamine receptor 2, GHR, GH, IGF-I, IGF-I receptor and insulin receptor (Ins-R) expression were performed in tumors that had grown and in control tumors with no progression. In the two tumors that grew during PEG treatment foci of cell hyperplasia were found and higher tissue expression of GH and Ins-R were reported.

In conclusion, the overall percentage of tumor growth during treatment with PEG is not different to that described for other treatment modalities of acromegaly ${ }^{70,84}$ Only $30 \%-40 \%$ are true cases of tumor progression after PEG treatment. The potential mechanisms involved are not well known but probably multiple factors including the loss of the suppressive effect of the SSA, a disruption of negative feedback IGF-I/ GH/GHRH (growth hormone releasing hormone), a possible disruption of IGF-I receptor/Ins-R pathways ${ }^{71}$ and obviously the intrinsic growth potential of the tumor should be taken into consideration. Most cases of tumor growth are mild; due to progression into the tumor cavities created by previous surgery so they are usually considered as not clinically relevant. ${ }^{68}$ Radiological follow-up of tumor volume during treatment with PEG is necessary but in most cases should not be different from the radiological follow-up conducted during SSA treatment. In this regard, performing MRI controls at 6 and 12 months after treatment initiation has been recently suggested as a standard follow-up strategy and if there is no tumor size change, MRI controls may be performed yearly thereafter. $^{2}$

\section{Liver dysfunction}

About 2.5\% of patients treated with PEG develop significant liver dysfunction with AST/ALT greater than three times the ULN. The incidence of this adverse event is higher during combination therapy with SSA,,$^{34,49,72,73}$ in patients with 


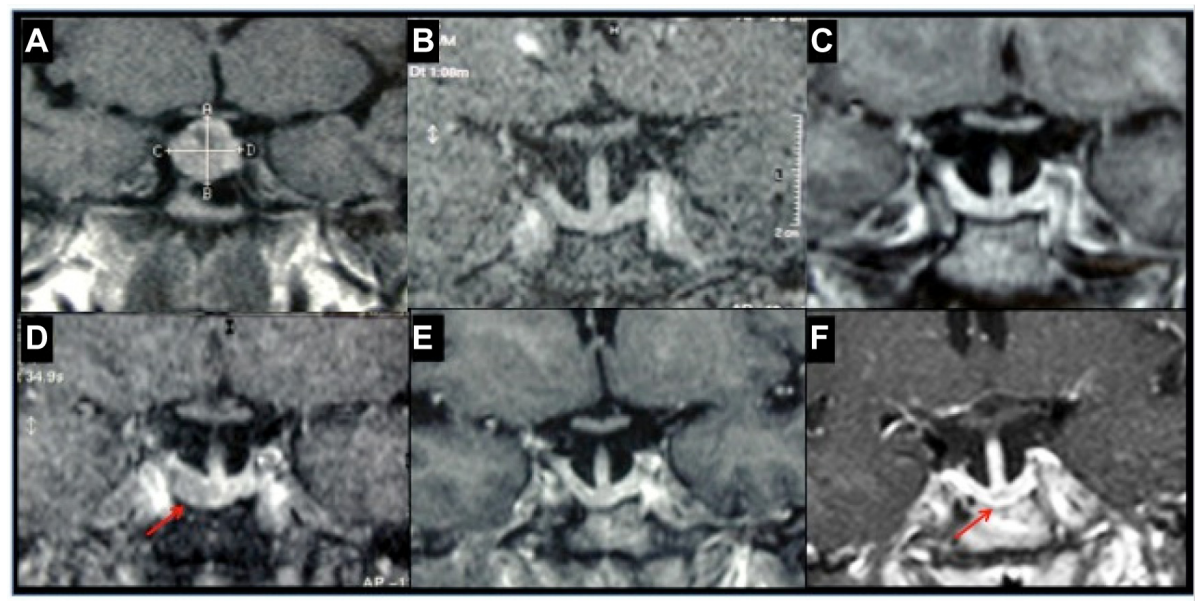

Figure I Follow-up magnetic resonance images showing changes in tumor size during different treatment regimes in a patient with acromegaly. Notes: (A) 1997: diagnosis of acromegaly. The patient underwent surgery and achieved normalization of GH/IGF-I levels, and postoperative MRI revealed no tumor remnant. (B) 200 I: biochemical and clinical recurrence of GH hypersecretion, without visible tumor on MRI. (C) 2004: after 3 years on maximum doses of SSA therapy combined with cabergoline, immediately prior to initiating PEG. (D) 2005: tumor growth (red arrow) after 15 months on PEG monotherapy, in which IGF-I levels were normalized. (E) 2006: after a second and unsuccessful surgery, coexisting with moderate GH hypersecretion. (F) 2008: after 18 months on treatment with maximum SSA doses with suboptimal control a new tumor growth (red arrow) was evidenced. The patient was then treated with pituitary irradiation.

Abbreviations: $\mathrm{GH}$, growth hormone; MRI, magnetic resonance imaging; SSA, somatostatin analogs; PEG, pegvisomant.

diabetes, with previous liver dysfunction and concomitant use of hepatotoxic drugs. ${ }^{73}$ Both hepatocellular and cholestatic dysfunction have been reported. ${ }^{74-76}$ The pathogenesis is unknown and has been considered as an unpredictable or idiosyncratic reaction..$^{74}$ One small study $(\mathrm{n}=36)$ performed in patients treated with PEG as monotherapy, ${ }^{77}$ found a close relationship between liver dysfunction and the UGT1A1*28 polymorphism of Gilbert's disease, directly or through other UGT1A1 genetic variations in linkage disequilibrium (UGT1A7*3 and $U G T 1 A 6^{*} 2$ polymorphisms). However, this result has not been confirmed in later studies. ${ }^{34,73} \mathrm{PEG}$ induced liver injury is frequently transient, and liver function tests revert to baseline spontaneously or after discontinuation of therapy. Permanent liver damage has not yet been described. ${ }^{26}$ Current guidelines suggest monitoring liver function tests monthly for the first 6 months and then every 6 months after starting PEG therapy, with consideration of discontinuation of PEG if there is a 3-fold elevation in transaminases levels. ${ }^{2}$

\section{Injection-site reactions}

Injection-site reactions have been reported in $2.2 \%$ of patients treated with PEG. Lipohypertrophy is the most frequent reaction, ${ }^{26}$ and is probably the consequence of a local imbalance between insulin (lipogenic) and of the loss of GH effect (lipolytic), resulting in a local fat hypertrophy without infiltration of inflammatory cells or fat necrosis. Lipohypertrophy seems to be more frequent in women and all injection sites may be affected. Lipohypertrophy can interfere with PEG absorption. It can be prevented with an adequate rotation of injection sites. Rarely, it can be severe thus requiring treatment discontinuation. ${ }^{78,79}$

\section{Other side effects}

PEG treatment can produce a functional GH deficiency. About $2.5 \%$ of patients treated with PEG showed IGF-I concentrations below the lowest limit of normal. ${ }^{29}$ Furthermore, functional GH deficiency can develop even with IGF-I concentrations within the normal range. ${ }^{80}$ To prevent the increased morbidity and mortality associated with GH deficiency, PEG therapy requires close monitoring and strict dose titration in order to maintain IGF-I concentration in the upper half of the normal range according to age and sex. Additionally, in a pilot study performed in five patients, ${ }^{81} \mathrm{PEG}$ treatment was followed by an increase in intra-abdominal fat comparing with active disease. PEG reverses the lipolytic effect of GH hypersecretion, improves insulin sensitivity, and increases body fat without change in weight. ${ }^{30}$ The selective increase in visceral fat could be related to higher expression of 11- $\beta$ hydroxysteroid dehydrogenase type 1 , whose activity is also increased by the absence of GH-dependent inhibition. ${ }^{81}$ Although this result has not been confirmed yet, it deserves to be considered, as visceral obesity is a risk factor for cardiovascular disease.

\section{Place of PEG in the management of acromegaly}

The introduction of PEG in clinical practice 12 years ago, represented a hope for a significant group of acromegalic 
Table 6 Economic cost of drugs for acromegaly in Spain in 2014

\begin{tabular}{|c|c|c|c|}
\hline \multirow[t]{2}{*}{ Mean PEG doses } & \multicolumn{2}{|l|}{ Annual costs $(€)$} & \multirow{2}{*}{$\begin{array}{l}\text { Total annual } \\
\text { cost }(€)\end{array}$} \\
\hline & Pegvisomant therapy & SSA therapy & \\
\hline \multicolumn{4}{|l|}{ PEG monotherapy (dose requirements) ${ }^{29}$} \\
\hline Controlled patients $(17,2 \mathrm{mg} / \mathrm{d})$ & 45,964 & - & 45,964 \\
\hline Uncontrolled patients (19.8 mg/d) & 52,912 & - & 52,912 \\
\hline \multicolumn{4}{|l|}{ Combined SSA + PEG (dose requirements) ${ }^{34}$} \\
\hline $80 \mathrm{mg}$ PEG/week and $30 \mathrm{mg} / 28 \mathrm{~d}$ octreotide LAR & 30,457 & 12,775 & 43,232 \\
\hline $80 \mathrm{mg} \mathrm{PEG} /$ week and $120 \mathrm{mg} / 28 \mathrm{~d}$ lanreotide autogel & 30,457 & 16,164 & 46,620 \\
\hline
\end{tabular}

Note: The average cost has been calculated based on the mean dose of PEG and SSA described in large series of treatment with PEG monotherapy and combination therapy by the use of PEG and SSA.

Abbreviations: PEG, pegvisomant; SSA, somatostatin analogs; d, day; LAR, long acting repeatable.

patients who remained with active disease despite the use of all available treatments. Surveillance studies have subsequently provided more information regarding the efficacy and safety of PEG during long-term treatment. ${ }^{24-26,29,30,83}$ In clinical practice, the efficacy of PEG has actually been reported to be somewhat lower than it was previously reported in pre-commercialization studies, but this could be largely explained by the different criteria for the definition of IGF-I normalization used in both types of studies (ie, lowest IGF-I versus latest IGF-I). Since there are no previous reports about tachyphylaxis ${ }^{21}$ or resistance to PEG and most cases with uncontrolled IGF-I were actually receiving submaximal PEG doses, we may expect a better biochemical control if dose titration is improved and better follow-up protocols are established. Beyond economic issues (Table 6), the use of insufficient dosage of PEG could be related to the physician's fear of potential adverse events, especially regarding tumor growth. This concern may also explain the increase in the combined use of PEG and SSA.
However, the increase in tumor volume after initiating PEG is not significantly different from that reported in other forms of therapy for acromegaly. Nevertheless, PEG treatment is not appropriate in cases of large tumors with local symptoms, or in active growing tumors. The discontinuation of PEG treatment because of adverse events is rare and thus should not limit the use of this drug to a significant extent.

While PEG was approved in Europe only for patients resistant or intolerant to SSA, approval in the USA was granted without this limitation. The Endocrine Society guidelines ${ }^{2}$ recommend medical therapy for patients with persistent disease after surgery. In those cases with moderate or severe disease without local mass-effect, the use of either SSA or PEG as initial adjuvant therapy is suggested. Also, following PEG's label approval in Europe, guidelines of the Italian Society of Endocrinology ${ }^{82}$ address the possibility of considering PEG as a primary post-surgical medical treatment in three specific settings: 1) patients already proven to be resistant to pre-surgical SSA treatment (at least 3-6 months of

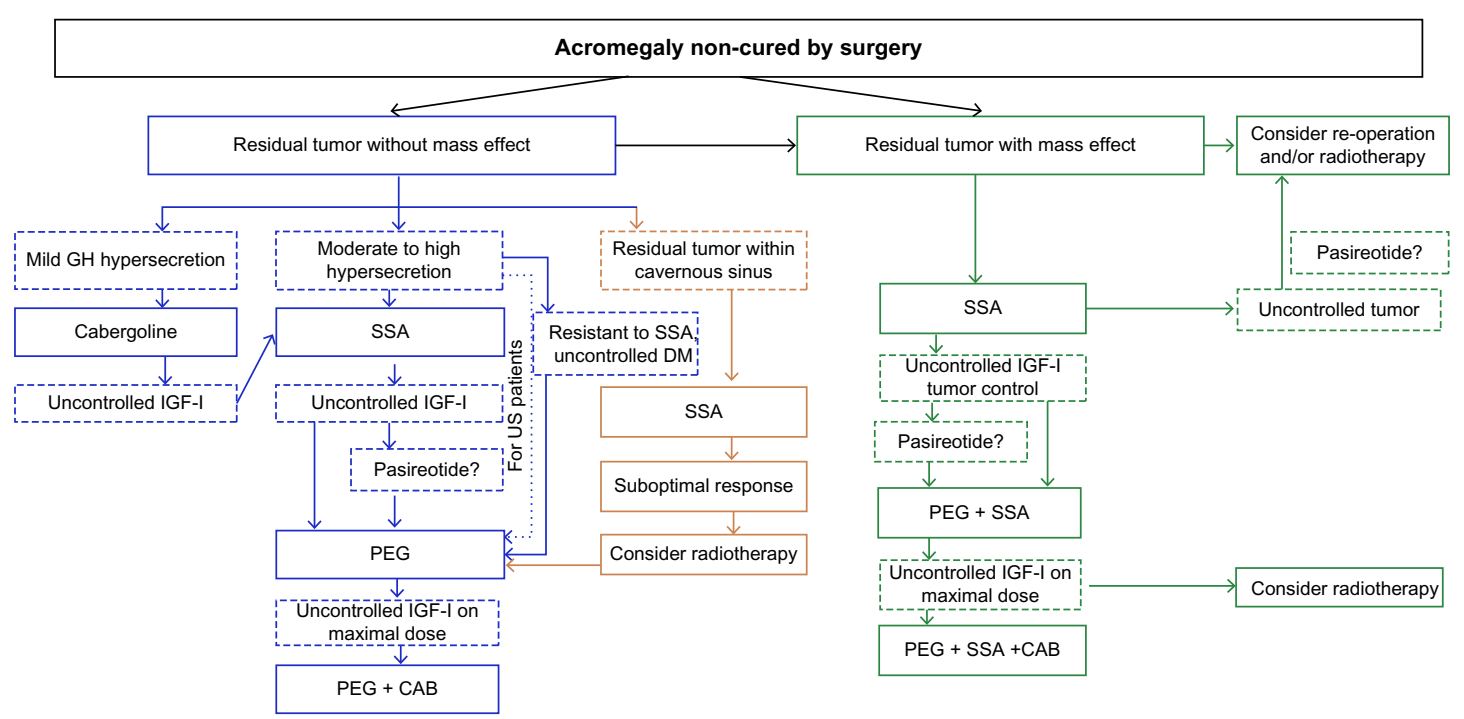

Figure 2 Pegvisomant (PEG) place in the algorithm of treatment of persistent acromegaly after surgery.

Abbreviations: CAB, cabergoline; GH, growth hormone; SSA, somatostatin analogs; DM, diabetes mellitus; US, United States. 
treatment, unless a higher than 75\% surgical debulking was achieved); 2) patients who underwent pituitary radiotherapy; and 3) patients with poorly controlled diabetes mellitus in whom SSA may potentially worsen glucose metabolism. In those cases with small tumor remnants in cavernous sinus without mass effect, especially in patients partially resistant to SSA, stereotactic radiotherapy or gamma-knife may be an option followed by PEG treatment.

For those patients with local mass effects (who are not candidates for debulking re-operation or radiotherapy) with tumor response to SSA but without biochemical control, the combination of SSA and PEG may be the best option.

On the other hand, however, combined treatment would not be useful in patients who have proven to be totally resistant to SSA, or in those cases who present minimal tumor remnant. Although the experience of the Dutch group ${ }^{34}$ regarding the use of combined treatment with SSA plus PEG as primary treatment is promising, especially if an expert neurosurgical team is not available, this is not currently recommended as a routine practice. When available, pasireotide could be an additional approach for non-diabetic acromegalic patients with persistent tumor local mass effects and who have not achieved biochemical control with first generation SSA treatment (Figure 2).

In conclusion, PEG is a safe and effective treatment. In recent years, indications, dosing, guidelines for follow-up, and new strategies of combined therapies have been developed to improve the outcome of patients with acromegaly.

\section{Acknowledgment}

This work was supported by grant FISS 11/00161 to IB.

\section{Disclosure}

The authors declare that there is no conflict of interest that could be perceived as prejudicing the impartiality of the research reported. IB has received lecture fees, advisor fees and a research grant from Pfizer and lecture fees from Novartis. MM has received lecture fees, advisor fees, and research grant from Pfizer, and lecture fees from Novartis and Ipsen.

\section{References}

1. Melmed S. Medical progress: Acromegaly. N Engl J Med. 2006;355(24): 2558-2573.

2. Katznelson L, Laws ER Jr, Melmed S, et al. Acromegaly: an endocrine society clinical practice guideline. J Clin Endocrinol Metab. 2014;99(11): 3933-3951.

3. Colao A, Auriemma RS, Lombardi G, Pivonello R. Resistance to somatostatin analogs in acromegaly. Endocr Rev. 2011;32(2):247-271.

4. Patel YC. Somatostatin and its receptor family. Front Neuroendocrinol. 1999;20(3):157-198.
5. Duran-Prado M, Saveanu A, Luque RM, et al. A potential inhibitory role for the new truncated variant of somatostatin receptor 5, sst5TMD4, in pituitary adenomas poorly responsive to somatostatin analogs. $J$ Clin Endocrinol Metab. 2010;95(5):2497-2502.

6. Gadelha MR, Kasuki L, Korbonits M. Novel pathway for somatostatin analogs in patients with acromegaly. Trends Endocrinol Metab. 2013; 24(5):238-246.

7. Gadelha MR, Bronstein MD, Brue T, et al. Pasireotide versus continued treatment with octreotide or lanreotide in patients with inadequately controlled acromegaly (PAOLA): a randomised, phase 3 trial. Lancet Diabetes Endocrinol. 2014;2(11):875-884.

8. Sandret L, Maison P, Chanson P. Place of cabergoline in acromegaly: a meta-analysis. J Clin Endocrinol Metab. 2011;96(5):1327-1335.

9. Higham CE, Atkinson AB, Aylwin S, et al. Effective Combination Treatment with Cabergoline and Low-Dose Pegvisomant in Active Acromegaly: A Prospective Clinical Trial. J Clin Endocrinol Metab. 2012;97(4):1187-1193.

10. Bernabeu I, Alvarez-Escola C, Paniagua AE, et al. Pegvisomant and cabergoline combination therapy in acromegaly. Pituitary. 2013;16(1):101-108.

11. Gent J, van Kerkhof P, Roza M, Bu G, Strous GJ. Ligand-independent growth hormone receptor dimerization occurs in the endoplasmic reticulum and is required for ubiquitin system-dependent endocytosis. Proc Natl Acad Sci U SA. 2002;99(15):9858-9863.

12. Brown RJ, Adams JJ, Pelekanos RA, et al. Model for growth hormone receptor activation based on subunit rotation within a receptor dimer. Nat Struct Mol Biol. 2005;12(9):814-821.

13. Carter-Su C, Smit LS. Signaling via JAK tyrosine kinases: growth hormone receptor as a model system. Recent Prog Horm Res. 1998;53:61-82.

14. Berg CA, Pokrajac A, Bidlingmaier M, Strasburger CJ, Shalet SM, Trainer PJ. Use of a GH receptor antagonist (GHRA) to explore the relationship between GH and IGF-I in adults with severe GH deficiency (GHD). Clin Endocrinol (Oxf). 2009;70(3):439-445.

15. Ross RJ, Esposito N, Shen XY, et al. A short isoform of the human growth hormone receptor functions as a dominant negative inhibitor of the full-length receptor and generates large amounts of binding protein. Mol Endocrinol. 1997;11(3):265-273.

16. Kopchick JJ, Parkinson C, Stevens EC, Trainer PJ. Growth hormone receptor antagonists: discovery, development, and use in patients with acromegaly. Endocr Rev. 2002;23(5):623-646.

17. Ross RJ, Leung KC, Maamra M, et al. Binding and functional studies with the growth hormone receptor antagonist, B2036-PEG (pegvisomant), reveal effects of pegylation and evidence that it binds to a receptor dimer. J Clin Endocrinol Metab. 2001;86(4):1716-1723.

18. Trainer PJ, Drake WM, Katznelson L, et al. Treatment of acromegaly with the growth hormone-receptor antagonist pegvisomant. $N$ Engl $J$ Med. 2000;342(16):1171-1177.

19. Madsen M, Fisker S, Feldt-Rasmussen U, et al. Circulating levels of pegvisomant and endogenous growth hormone during prolonged pegvisomant therapy in patients with acromegaly. Clin Endocrinol (Oxf). 2014;80(1):92-100.

20. Paisley AN, Hayden K, Ellis A, Anderson J, Wieringa G, Trainer PJ. Pegvisomant interference in $\mathrm{GH}$ assays results in underestimation of GH levels. Eur J Endocrinol. 2007;156(3):315-319.

21. van der Lely AJ, Hutson RK, Trainer PJ, et al. Long-term treatment of acromegaly with pegvisomant, a growth hormone receptor antagonist. Lancet. 2001;358(9295):1754-1759.

22. Herman-Bonert VS, Zib K, Scarlett JA, Melmed S. Growth hormone receptor antagonist therapy in acromegalic patients resistant to somatostatin analogs. J Clin Endocrinol Metab. 2000;85(8):2958-2961.

23. Drake WM, Parkinson C, Akker SA, Monson JP, Besser GM, Trainer PJ. Successful treatment of resistant acromegaly with a growth hormone receptor antagonist. Eur J Endocrinol. 2001;145(4):451-456.

24. Buchfelder M, Schlaffer S, Droste M, et al. The German ACROSTUDY: past and present. Eur J Endocrinol. 2009;161 Suppl 1:S3-S10.

25. Trainer PJ. ACROSTUDY: the first 5 years. Eur J Endocrinol. 2009;161 Suppl 1:S19-S24. 
26. van der Lely AJ, Biller BM, Brue T, et al. Long-term safety of pegvisomant in patients with acromegaly: comprehensive review of 1288 subjects in ACROSTUDY. J Clin Endocrinol Metab. 2012;97(5):1589-1597.

27. Brue T, Castinetti F, Lundgren F, Koltowska-Haggstrom M, Petrossians P; ACROSTUDY investigators. Which patients with acromegaly are treated with pegvisomant? An overview of methodology and baseline data in ACROSTUDY. Eur J Endocrinol. 2009;161 Suppl 1:S11-S17.

28. Brue T. ACROSTUDY: Status update on 469 patients. Horm Res. 2009;71 Suppl 1:34-38.

29. Freda PU, Gordon MB, Kelepouris N, Jonsson P, Koltowska-Haggstrom M, van der Lely AJ. Long-Term Treatment with Pegvisomant as Monotherapy in Patients with Acromegaly: Experience from Acrostudy. Endocr Pract. 2014;4:1-32.

30. Schreiber I, Buchfelder M, Droste M, et al. Treatment of acromegaly with the $\mathrm{GH}$ receptor antagonist pegvisomant in clinical practice: safety and efficacy evaluation from the German Pegvisomant Observational Study. Eur J Endocrinol. 2007;156(1):75-82.

31. Marazuela M, Lucas T, Alvarez-Escola C, et al. Long-term treatment of acromegalic patients resistant to somatostatin analogues with the GH receptor antagonist pegvisomant: its efficacy in relation to gender and previous radiotherapy. Eur J Endocrinol. 2009;160(4):535-542.

32. Higham CE, Chung TT, Lawrance J, Drake WM, Trainer PJ. Long-term experience of pegvisomant therapy as a treatment for acromegaly. Clin Endocrinol (Oxf). 2009;71(1):86-91.

33. Sesmilo G, Resmini E, Bernabeu I, et al. Escape and lipodystrophy in acromegaly during pegvisomant therapy, a retrospective multicentre Spanish study. Clin Endocrinol (Oxf). 2014;81(6):883-890.

34. Neggers SJ, Franck SE, de Rooij FW, et al. Long-term efficacy and safety of pegvisomant in combination with long-acting somatostatin analogs in acromegaly. J Clin Endocrinol Metab. 2014;99(10):3644-3652.

35. Pereira AM, Biermasz NR, Roelfsema F, Romijn JA. Pharmacologic therapies for acromegaly: a review of their effects on glucose metabolism and insulin resistance. Treat Endocrinol. 2005;4(1):43-53.

36. Mazziotti G, Floriani I, Bonadonna S, Torri V, Chanson P, Giustina A. Effects of somatostatin analogs on glucose homeostasis: a metaanalysis of acromegaly studies. J Clin Endocrinol Metab. 2009;94(5): $1500-1508$.

37. Urbani C, Sardella C, Calevro A, et al. Effects of medical therapies for acromegaly on glucose metabolism. Eur J Endocrinol. 2013;169(1): 99-108.

38. Rose DR, Clemmons DR. Growth hormone receptor antagonist improves insulin resistance in acromegaly. Growth Horm IGF Res. 2002;12(6):418-424.

39. Drake WM, Rowles SV, Roberts ME, et al. Insulin sensitivity and glucose tolerance improve in patients with acromegaly converted from depot octreotide to pegvisomant. Eur J Endocrinol. 2003;149(6):521-527.

40. Barkan AL, Burman P, Clemmons DR, et al. Glucose homeostasis and safety in patients with acromegaly converted from long-acting octreotide to pegvisomant. J Clin Endocrinol Metab. 2005;90(10):5684-5691.

41. Jorgensen JO, Moller L, Krag M, Billestrup N, Christiansen JS. Effects of growth hormone on glucose and fat metabolism in human subjects. Endocrinol Metab Clin North Am. 2007;36(1):75-87.

42. Lindberg-Larsen R, Moller N, Schmitz O, et al. The impact of pegvisomant treatment on substrate metabolism and insulin sensitivity in patients with acromegaly. J Clin Endocrinol Metab. 2007;92(5):1724-1728.

43. Droste M, Domberg J, Buchfelder M, et al. Therapy of acromegalic patients exacerbated by concomitant type 2 diabetes requires higher pegvisomant doses to normalise IGF1 levels. Eur J Endocrinol. 2014;171(1):59-68.

44. Berg C, Petersenn S, Lahner H, et al. Cardiovascular risk factors in patients with uncontrolled and long-term acromegaly: comparison with matched data from the general population and the effect of disease control. J Clin Endocrinol Metab. 2010;95(8):3648-3656.

45. Parkinson C, Drake WM, Wieringa G, Yates AP, Besser GM, Trainer PJ. Serum lipoprotein changes following IGF-I normalization using a growth hormone receptor antagonist in acromegaly. Clin Endocrinol (Oxf). 2002;56(3):303-311.
46. Sesmilo G, Fairfield WP, Katznelson L, et al. Cardiovascular risk factors in acromegaly before and after normalization of serum IGF-I levels with the GH antagonist pegvisomant. J Clin Endocrinol Metab. 2002;87(4):1692-1699.

47. van der Lely AJ, Gomez R, Heissler JF, et al. Pregnancy in acromegaly patients treated with pegvisomant. Endocrine. Epub December 27, 2014.

48. Feenstra J, de Herder WW, ten Have SM, et al. Combined therapy with somatostatin analogues and weekly pegvisomant in active acromegaly. Lancet. 2005;365(9471):1644-1646.

49. Neggers SJ, de Herder WW, Janssen JA, Feelders RA, van der Lely AJ. Combined treatment for acromegaly with long-acting somatostatin analogs and pegvisomant: long-term safety for up to 4.5 years (median 2.2 years) of follow-up in 86 patients. Eur J Endocrinol. 2009;160(4): 529-533.

50. Neggers SJ, van Aken MO, de Herder WW, et al. Quality of life in acromegalic patients during long-term somatostatin analog treatment with and without pegvisomant. JClin Endocrinol Metab. 2008;93(10): 3853-3859.

51. Trainer PJ, Ezzat S, D’Souza GA, Layton G, Strasburger CJ. A randomized, controlled, multicentre trial comparing pegvisomant alone with combination therapy of pegvisomant and long-acting octreotide in patients with acromegaly. Clin Endocrinol (Oxf). 2009;71(4): 549-557.

52. Jorgensen JO, Feldt-Rasmussen U, Frystyk J, et al. Cotreatment of acromegaly with a somatostatin analog and a growth hormone receptor antagonist. J Clin Endocrinol Metab. 2005;90(10):5627-5631.

53. van der Lely AJ, Bernabeu I, Cap J, et al. Coadministration of lanreotide Autogel and pegvisomant normalizes IGF1 levels and is well tolerated in patients with acromegaly partially controlled by somatostatin analogs alone. Eur J Endocrinol. 2011;164(3):325-333.

54. Fisker S. Physiology and pathophysiology of growth hormone-binding protein: methodological and clinical aspects. Growth Horm IGF Res. 2006;16(1):1-28.

55. Leung KC, Johannsson G, Leong GM, Ho KK. Estrogen regulation of growth hormone action. Endocr Rev. 2004;25(5):693-721.

56. Parkinson C, Burman P, Messig M, Trainer PJ. Gender, body weight, disease activity, and previous radiotherapy influence the response to pegvisomant. J Clin Endocrinol Metab. 2007;92(1):190-195.

57. US Food and Drug Administration [homepage on the Internet]. Pegvisomant FDA Approval Package. Clinical Pharmacology and Biopharmaceutics review and Medical review; 2003. Available from: http://www.accessdata.fda.gov/drugsatfda_docs/nda/2003/021106_ somavert.cfm. Accessed January 17, 2015.

58. Leung KC, Doyle N, Ballesteros M, Waters MJ, Ho KK. Insulin regulation of human hepatic growth hormone receptors: divergent effects on biosynthesis and surface translocation. J Clin Endocrinol Metab. 2000; 85(12):4712-4720.

59. Wurzburger MI, Prelevic GM, Sonksen PH, Wheeler M, Balint-Peric L. Effect of recombinant human growth hormone treatment on insulin-like growth factor (IGF-I) levels in insulin-dependent diabetic patients. Acta Diabetol. 1995;32(2):131-134.

60. Wurzburger MI, Prelevic GM, Sonksen PH, Balint-Peric LA, Wheeler M. The effect of recombinant human growth hormone on regulation of growth hormone secretion and blood glucose in insulindependent diabetes. J Clin Endocrinol Metab. 1993;77(1):267-272.

61. Kratzsch J, Keliner K, Zilkens T, Schmidt-Gayk H, Selisko T, Scholz GH. Growth hormone-binding protein related immunoreactivity is regulated by the degree of insulinopenia in diabetes mellitus. Clin Endocrinol (Oxf). 1996;44(6):673-678.

62. Mercado M, Gonzalez B, Sandoval C, et al. Clinical and biochemical impact of the $\mathrm{d} 3$ growth hormone receptor genotype in acromegaly. J Clin Endocrinol Metab. 2008;93(9):3411-3415.

63. Bianchi A, Mazziotti G, Tilaro L, et al. Growth hormone receptor polymorphism and the effects of pegvisomant in acromegaly. Pituitary. 2009;12(3):196-199.

64. Bernabeu I, Alvarez-Escola C, Quinteiro C, et al. The exon 3-deleted growth hormone receptor is associated with better response to pegvisomant therapy in acromegaly. J Clin Endocrinol Metab. 2010;95(1): 222-229. 
65. Filopanti M, Olgiati L, Mantovani G, et al. Growth hormone receptor variants and response to pegvisomant in monotherapy or in combination with somatostatin analogs in acromegalic patients: a multicenter study. J Clin Endocrinol Metab. 2012;97(2):E165-E172.

66. Akin F, Turgut S, Cirak B, Kursunluoglu R. IGF(CA)19 and IGFBP3-202A/C gene polymorphism in patients with acromegaly. Growth Horm IGF Res. 2010;20(6):399-403.

67. Ramos-Levi AM, Marazuela M, Paniagua A, et al. Analysis of Igf(Ca)19 and Igfpb3 202a/C Gene Polymorphisms in Patients with Acromegaly: Association with Clinical Presentation and Response to Treatments. Eur J Endocrinol. 2015;172(2):115-122.

68. Buchfelder M, Weigel D, Droste M, et al. Pituitary tumor size in acromegaly during pegvisomant treatment: experience from MR reevaluations of the German Pegvisomant Observational Study. Eur J Endocrinol. 2009;161(1):27-35.

69. Marazuela M, Paniagua AE, Gahete MD, et al. Somatotroph tumor progression during pegvisomant therapy: a clinical and molecular study. $J$ Clin Endocrinol Metab. 2011;96(2):E251-E259.

70. Besser GM, Burman P, Daly AF. Predictors and rates of treatmentresistant tumor growth in acromegaly. Eur J Endocrinol. 2005;153(2): 187-193.

71. Gallagher EJ, LeRoith D. The proliferating role of insulin and insulinlike growth factors in cancer. Trends Endocrinol Metab. 2010;21(10): 610-618.

72. Neggers SJ, van Aken MO, Janssen JA, Feelders RA, de Herder WW, van der Lely AJ. Long-term efficacy and safety of combined treatment of somatostatin analogs and pegvisomant in acromegaly. J Clin Endocrinol Metab. 2007;92(12):4598-4601.

73. Filopanti M, Barbieri AM, Mantovani G, et al. Role of UGT1A1 and $\mathrm{ADH}$ gene polymorphisms in pegvisomant-induced liver toxicity in acromegalic patients. Eur J Endocrinol. 2013;170(2):247-254.

74. Biering H, Saller B, Bauditz J, et al. Elevated transaminases during medical treatment of acromegaly: a review of the German pegvisomant surveillance experience and a report of a patient with histologically proven chronic mild active hepatitis. Eur J Endocrinol. 2006;154(2): 213-220.
75. Feenstra J, van Aken MO, de Herder WW, Feelders RA, van der Lely AJ. Drug-induced hepatitis in an acromegalic patient during combined treatment with pegvisomant and octreotide long-acting repeatable attributed to the use of pegvisomant. Eur J Endocrinol. 2006;154(6): 805-806.

76. Bernabeu I, Cameselle-Teijeiro J, Casanueva F, Marazuela M. Pegvisomant-induced cholestatic hepatitis with jaundice in a patient with Gilbert's syndrome. Eur J Endocrinol. 2009;160(5):869-872.

77. Bernabeu I, Marazuela M, Lucas T, et al. Pegvisomant-induced liver injury is related to the UGT1A $1 * 28$ polymorphism of Gilbert's syndrome. J Clin Endocrinol Metab. 2010;95(5):2147-2154.

78. Bonert VS, Kennedy L, Petersenn S, Barkan A, Carmichael J, Melmed S. Lipodystrophy in patients with acromegaly receiving pegvisomant. J Clin Endocrinol Metab. 2008;93(9):3515-3518.

79. Marazuela M, Dauden E, Ocon E, Moure D, Nattero L. Pegvisomantinduced lipohypertrophy: report of a case with histopathology. Ann Intern Med. 2007;147(10):741-743.

80. Paisley AN, Trainer PJ. The challenges of reliance on insulin-like growth factor I in monitoring disease activity in patients with acromegaly. Horm Res. 2004;62 Suppl 1:83-88.

81. Plockinger U, Reuter T. Pegvisomant increases intra-abdominal fat in patients with acromegaly: a pilot study. Eur J Endocrinol. 2008;158(4): 467-471.

82. Giustina A, Ambrosio MR, Beck Peccoz P, et al. Use of Pegvisomant in acromegaly. An Italian Society of Endocrinology guideline. J Endocrinol Invest. 2014;37(10):1017-1030.

83. Grottoli S, Maffei P, Bogazzi F, et al. ACROSTUDY: the Italian experience. Endocrine. Epub August 23, 2014.

84. Buhk JH, Jung S, Psychogios MN, et al. Tumor volume of growth hormone-secreting pituitary adenomas during treatment with pegvisomant: A prospective multicenter study. J Clin Endocrinol Metab. 2010;95(2):552-558.
Research and Reports in Endocrine Disorders

\section{Publish your work in this journal}

Research and Reports in Endocrine Disorders is an international, peerreviewed, open access journal publishing original research, reports, reviews and commentaries on all areas of endocrinology, endocrine disorders and therapeutic interventions. The manuscript management system is completely online and includes a very quick and fair
Dovepress

peer-review system. Visit http://www.dovepress.com/testimonials.php to read real quotes from published authors. 